\title{
Study on Desertification Monitoring from 2000 to 2014 and Its Driving Factors through Remote Sensing in Ningxia, China
}

\author{
ZHAO Zhuowen, WU Qinshu* \\ Jiangsu Institute of Surveying and Mapping, Nanjing, Jiangsu, China - 18622289689@163.com \\ Commission III, WG III/1
}

KEY WORDS: Ningxia, Desertification, Rainfall Use Efficiency, Grey Relational Analysis, Driving Factors, Precipitation

\begin{abstract}
:
Due to the implementation of national policy, the desertification in Ningxia has been gradually reduced, but the overall situation of desertification is still serious. Rainfall Use Efficiency(RUE) can make some improvement to the problem that the precipitation has a great influence on vegetation in arid area and fully reflect the dynamic characteristics of desertification. Using the MOD13Q1 data, land use classification map, as well as non-remote sensing data such as meteorological data and social statistics data, the paper carries out the evaluation of the status of desertification based on RUE through spatial trend analysis, gravity center migration model. The driving factors of desertification are quantitatively analyzed by using grey relational analysis. Our study demonstrated that RUE in most parts of Ningxia showed a trend of improvement, mainly located in central and southern Ningxia. The area where desertification occurred from 2000 to 2014 accounted for 7.79\%, mainly distributed in Helan Mountain, Liupan Mountain, Yinchuan Central. The proportion of desertification decreased gradually from 2005 to 2014, and the center of gravity of desertification had a tendency to migrate to northern Ningxia. By analyzing the driving factors, RUE had negative correlations with precipitation and relative humidity and there was no significant correlation between RUE and average temperature and sunshine hours. RUE was positively correlated with GDP, grain yield and number of sheep. On the basis of the results of grey relational analysis, it was found that sunshine hours, average temperature, relative humidity, population were the main influencing factors of desertification.
\end{abstract}

\section{INTRODUCTION}

Land desertification is a dynamic evolution process occurring in arid and semi-arid areas. Climate changes, human activities, and urban economic development have led to land desertification. Land desertification, as the most serious ecological problem and economic problem at present, has seriously affected the social and economic sustainable development of our country. Therefore, strengthening the dynamic monitoring of desertification in terms of regional units has important guidance for China's ecological environment construction and socio-economic development (Wei et al., 2014).

Vegetation is the most element part of the ecosystem. Degradation of vegetation is a sensitive indicator of desertification (Zhou, 2010). Many scholars have monitored the status of desertification through vegetation indicators (Piao et al., 2005; Wang et al., 2007). However, precipitation is an important factor affecting vegetation cover in arid and semi-arid regions. Reduce in vegetation coverage due to drought cannot be considered as desertification. Foreign scholars have proposed to use Rainfall Use Efficiency (RUE) to study desertification (Fensholt et al., 2011; Xu, 2013), which can avoid the problem of large impact of precipitation on the vegetation to a certain extent and has a strong indication of land degradation (Gao et al., 2005).Hountondji et al. (Hountondji et al., 2006) used RUE to analyze desertification in Burkina Faso from 1982 to 1999. Barrio et al. (Barrio et al., 2010) monitored and evaluated the desertification situation by analyzing changes in RUE in the Iberian Peninsula in the past 11 years. Yin He, and Wei Zhenfeng et al. (Yin et al., 2011; Wei et al., 2014) analyzed the distribution of desertification in different research areas through the trend of
RUE over time. Most studies have confirmed that RUE can comprehensively reflect the change characteristics of land production capacity and effectively explain the status of desertification $(\mathrm{Xu}, 2013)$. Meanwhile, the analysis of desertdriving factors is directly related to the proposed and effective implementation of desertification control measures (Kang et al., 2014). The driving factors of desertification mainly include climatic factors and human factors. There are relatively more studies on climatic factors. The impact of human activities mainly adopts residual method, modified NDVI method and RUE to eliminate the effect of precipitation on land desertification (Peng et al., 2010; Li et al., 2011), or principal component analysis and factor analysis to analyze human activity intensity (Jiang et al., 2008; Zhang et al., 2013). Wei Zhenfeng et al. (Wei et al., 2014) used the residual method to remove the influence of precipitation and obtained the influence of human activities on desertification in the Loess Plateau. Sun Jianguo et al. (Sun et al., 2012) used binary quadratic equation to simulate vegetation-climate temporal and spatial relationships to analyze the relative roles of climatic factors and human factors in desertification in Yulin. Zhang Xibiao et al. (Zhang et al., 2013) quantitatively analyzed the main factors of desertification in the Loess Plateau through principal component analysis.

Ningxia is located in the transitional zone of plateaus and mountains, and the transitional zone between the eastern monsoon region and the northwest arid region, which is one of the areas with a wide distribution of desertification. The status and dynamic evaluation of desertification in Ningxia is quite representative and typical and has important practical significance for its prevention and control. Most studies on Ningxia are based on lower resolution data, and are based on 
desertification landscape characteristics to evaluate the status of desertification, which rarely analyzed the dynamics of desertification, especially the role of driving factors in the process of desertification has not been further studied. Based on the actual situation of the region, the paper uses the trend of RUE to evaluate the dynamic of desertification in Ningxia, and quantitatively analyzes the influence of natural factors and socioeconomic factors in the desertification process, comprehensively evaluating the causes of desertification in Ningxia, for purpose of providing a scientific basis for ecological construction in Ningxia.

\section{DATA AND METHODS}

\subsection{Study area}

Ningxia Hui Autonomous region (104 $17^{\prime}-107^{\circ} 39^{\prime}$ E, $35^{\circ} 14^{\prime}$ $\left.39^{\circ} 23^{\prime}\right)$ is located in middle-up stream of Yellow River. Ningxia is bordered by Shaanxi Province to the East, Gansu Province to the South and the Inner Mongolia Autonomous Region to the North. The whole territory covers an area of $66400 \mathrm{~km} 2$ (Figure 1). According to the features of topography, climate, hydrology and others, Ningxia is divided into Hilly mountain area, Arid area, and Yellow river irrigation area from south to north. It is significantly different for the climate of Ningxia, the average annual precipitation in the northern region is about $200 \mathrm{ml}$, but convenient irrigation conditions bring developed agriculture. There is mainly the desert grassland in the central region where the annual precipitation is $200 \sim 350 \mathrm{~mm}$. The southern region is the area with the most precipitation in Ningxia, with annual precipitation of $350-600 \mathrm{~mm}$ and abundant forest resources. Ningxia has successively implemented the policies of Returning farmland to forests project, Yellow River irrigation project and National natural forest resource protection project, which have improved the situation of desertification to some extent. However, Ningxia is one of the areas where desertification is widely distributed and it is necessary to conduct in-depth study on the dynamics of desertification.

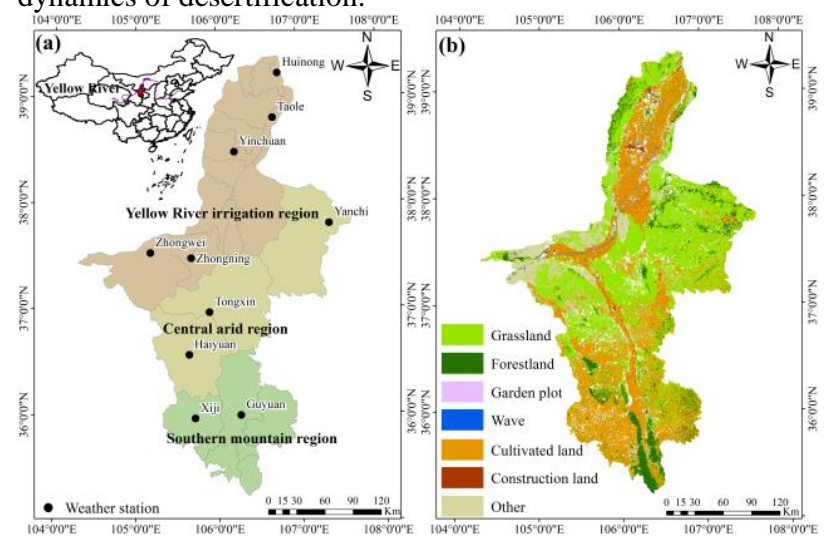

Figure 1. Location (a) and the types of vegetation cover (b) of the study area

\subsection{Data sources and preprocessing}

NDVI is downloaded from United States Geological Survey (USGS, http://glovis.usgs.gov/). We select MOD13Q1 of MODIS product from 2000 to 2014, the time and the spatial resolution of which are $16 \mathrm{~d}$ and $250 \mathrm{~m}$ respectively. Performing data format conversion, projection transformation with MODIS ReProjection Tools (MRT). At the same time, in order to remove the influence of the atmosphere and clouds as much as possible, the Maximum Value Composite (MVC) method is used to synthesize the monthly maximum NDVI.
Meteorological data and Land use classification data are collected from "National Science and Technology Infrastructure Platform-National Earth System Data Sharing Platform-LakeWatershed Scientific Data Center" (http://lake.geodata.cn). We select the monthly data of the average temperature, precipitation, sunshine hours, and average relative humidity of ten meteorological stations in Ningxia during growing season (MaySeptember) from 1980 to 2014. The average temperature and average relative humidity in the growing season are obtained by calculating the average values of five months. The precipitation and sunshine hours in the growing season are the sum of five months. According to national land classification standards, the land is classified into forestland, cultivated field, grassland, garden, construction land, water and other by ArcGIS.

Statistical data which include population, per capita GDP, grain yield and the number of sheep are all extracted from the Ningxia Statistical Yearbook (2001-2015). Converting the statistical data into raster data with the same projection type and the same raster size as the NDVI data by vector to raster tool.

\subsection{Methods}

2.3.1 Spatial interpolation of meteorological factors: Due to the sparseness of weather stations in Ningxia, overly sparse meteorological stations may cause meteorological factor distribution deviations in non-meteorological station area. $\mathrm{Gu}$ Zhihui (Gu et al., 2006) and Wang Zhi (Wang et al., 2011) have found that the accuracy of interpolation was significantly improved by adding simulated meteorological stations to enrich the amount of meteorological data. Therefore, this paper adopts the actual measurement stations and simulation stations which is added in the blank area to interpolate to obtain result.

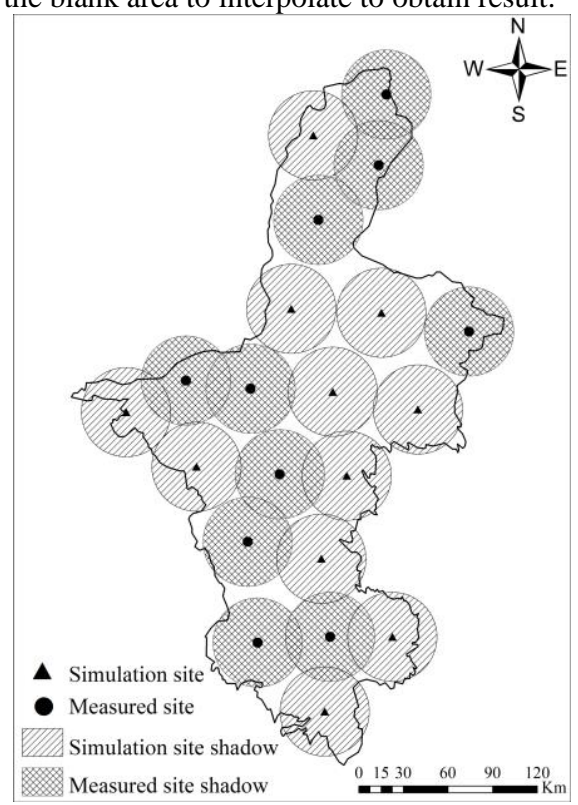

Figure 2. Distribution of simulated weather station

Specific process: based on the geostatistical analysis of the actual measurement stations in Ningxia, the result shows that $30 \mathrm{~km}$ is a suitable sampling area. Then, we draw circular influence areas with a radius of $30 \mathrm{~km}$ in the non-meteorological site distribution area and extract the center of each circle as an additional meteorological station by the feature to point tool. A total of 11 weather stations have been added, as shown in Figure 2. Pearson correlation analysis is used to identify the relationship between annual meteorological elements (precipitation, average 
temperature, sunshine duration and average relative humidity) and terrain factor (longitude, latitude, slope, aspect and elevation of each meteorological station). The terrain factor that has the highest correlation with meteorological factors are used to establish regression equation with corresponding meteorological factor respectively to calculate the value of the simulated meteorological factors. Finally, Kriging interpolation is used for spatial interpolation of the measured and simulated sites (Gu et al., 2006).

\subsubsection{Desertification monitoring and evaluation:}

a. Estimation of Rainfall Use Efficiency

Related studies have discovered that the change of NDVI is mainly controlled by the change of vegetation cover in arid and semi-arid regions, but less affected by changes of the optical thickness of the canopy, especially in the growing season (Gao et al., 2005), so NDVI is regularly used to replace NPP.

$$
R U E=N P P / P
$$

Where $R U E$ means Rainfall Use Efficiency in growing season, $N P P$ is replaced with the cumulative value of NDVI, $P$ means precipitation.

\section{b. Trend analysis}

Sen's slope is more advantageous in the trend analysis methods, which does not need to consider the absence of data in the sequence and will not be disturbed by outliers in the sequence. The formula is as follows:

$$
Q=\operatorname{median} \frac{X_{j}-X_{i}}{j-i} \quad 1<i<j<n
$$

where, $Q$ means the trends of RUE variation, $\mathrm{n}$ means the total year (n=15), $X_{i}$ and $X_{j}$ represent the RUE of the time series $i$ and $\mathrm{j}, Q$ is greater than 0 , indicating that the sequence is in a rising trend, and $\mathrm{Q}$ is less than 0 , indicating that the sequence is in a decreasing trend.

Mann-kendall (M-K) test is used to test the significance of change trend which can eliminate the outliers of the sequence. The specific inspection process is as follows:

$$
\begin{gathered}
\tau=\sum_{i=1}^{n-1} \sum_{j=i+1}^{n} \operatorname{sign}\left(x_{j}-x_{i}\right) \\
\operatorname{sign}\left(x_{j}-x_{i}\right)=\left\{\begin{array}{ll}
1 & x_{j}-x_{i}>0 \\
0 & x_{j}-x_{i}=0 \\
-1 & x_{j}-x_{i}<0
\end{array}\right\} \\
U_{M K}=\left\{\begin{array}{cc}
(\tau-1) /[\operatorname{Var}(\tau)]^{\frac{1}{2}} & \tau>0 \\
0 & \tau=0 \\
(\tau+1) /[\operatorname{Var}(\tau)]^{\frac{1}{2}} & \tau<0
\end{array}\right\} \\
\operatorname{Var}(\tau)=\frac{n(n-1)(2 n+5)}{18}
\end{gathered}
$$

Where $\alpha$ is usually defined as a given level of significance, generally taking $\alpha=0.05$, when $\left|U_{M K}\right|>u_{1-\alpha / 2}$, we judge a significant change in the 0.05 confidence level.

c. R/S model

For the time series $\left\{\operatorname{NDVI}_{(t)}\right\} \quad(t=1,2, \ldots, n)$, the mean sequence is defined:

$$
\overline{\operatorname{NDVI}}_{(T)}=\frac{1}{T} \sum_{t=1}^{T} \mathrm{NDVI}_{(T)} \quad T=1,2, \quad \ldots, n
$$

(1) Cumulative deviation: $X_{(t, T)}=\sum_{t=1}^{t}\left(\mathrm{NDVI}_{(t)}-\overline{\mathrm{NDVI}}_{(T)}\right)(8)$

(2)Extreme value: $R_{(t)}=\max _{1 \leq t \leq T} X_{(t, T)}-\min _{1 \leq t \leq T} X_{(t, T)}$

(3)Standard deviation: $S_{(T)}=\left[\frac{1}{T} \sum_{t}^{T}\left(\operatorname{NDVI}_{(t)}-\mathrm{NDVI}_{(T)}\right)^{2}\right]^{\frac{1}{2}}(10)$

Making $R_{(t)} / S_{(T)}=(c t)^{H}$, the relationship between $\ln R(t) /$ $S(t)$ and $\ln t$ is plotted in the coordinate system, the slope of the fitted line is the Hurst index $H$. When $H=0.5$, the trend of sequence is less affected by the past and is random; when $H>0.5$, the sequence has strong persistence; when $H<0.5$, the sequence has anti-persistence (Wen et al., 2015).

d. Center of gravity migration model

The migration of center of gravity accurately reflects the process of the evolution of factors in space. The formula for calculating the center of gravity of desertification in the $t$-th year is:

$$
\begin{aligned}
& X_{t}=\sum_{i=1}^{n}\left(C_{i t} \times X_{i t}\right) / \sum_{i=1}^{n} C_{i t} \\
& Y_{t}=\sum_{i=1}^{n}\left(C_{i t} \times Y_{i t}\right) / \sum_{i=1}^{n} C_{i t}
\end{aligned}
$$

Where $X_{t}$ and $Y_{t}$ mean the latitude and longitude of the center of gravity of desertification; $C_{i t}$ represents the area of the $\mathrm{t}$-th year of the i-th desertification patch; $X_{i t}$ and $Y_{i t}$ mean the latitude and longitude of the center of gravity of the $t$-th year of the $i$-th desertification patch.

\subsubsection{Driver factor analysis:}

\section{a. Correlation analysis}

Person correlation coefficient is the most widely used correlation coefficient used to measure the degree of linear correlation between two variables. The formula is:

$$
r=\frac{\sum_{i=1}^{n}\left(x_{i}-\bar{x}\right)\left(y_{i}-\bar{y}\right)}{\sqrt{\sum_{i=1}^{n}\left(x_{i}-\bar{x}\right)^{2} \sum_{i=1}^{n}\left(y_{i}-\bar{y}\right)^{2}}}
$$

Among them, $x_{i}$ and $y_{i}$ represent the values of two variables, $\bar{x}$ and $\bar{y}$ are the average of two variables, $\mathrm{r}$ is the correlation coefficient. The correlation is divided into the following ranks according to significant test table: extremely significant negative correlation ( $r<-0.641)$, significant negative correlation ($0.641<r<-0.514)$, insignificant negative correlation ($0.514<r<0)$, insignificant positive correlation $(0<r<0.514)$, significant positive correlation $(0.514<r<0.641)$, and extremely significant positive correlation $(r>0.641)$.

\section{b. Grey relational analysis}

Grey correlation analysis measures the degree of correlation of various factors by analyzing whether the trends of different factors are consistent. Compared with regression analysis and correlation analysis, it requires less data, and it is a dynamic process that can achieve correlation analysis of dynamic history between different time series (Xu et al., 2013).

(1)Standardization (non-dimensionalization)

$$
\begin{gathered}
\bar{x}_{i}=\frac{1}{15} \sum_{t=1}^{15} x_{i}(t), \quad X_{i}(t)=x_{i}(t) / \bar{x}_{i} \\
\left\{X_{i}(t)\right\}=\left\{X_{i}(1), X_{i}(2), \ldots, X_{i}(15)\right\}
\end{gathered}
$$


where, $t$ means the total year $(\mathrm{t}=15), \bar{x}_{i}$ represents the average of each factor, $X_{i}(t)$ is the standardized series of factors.

(2)Correlation coefficient $\zeta_{X_{i}}(t)$

In the article, setting Rainfall Use Efficiency from 2000 to 2014 as the reference sequence $X_{0}$, and eight impact factors as the comparison sequence which are denoted as $X_{1}, X_{2}, \ldots, X_{i}$, $(i=1,2, \ldots, 8)$ respectively. Calculating the correlation coefficient of each comparison sequence and reference sequence at each time:

$$
\zeta_{X_{i}}(t)=\frac{\min _{i} \min _{t}\left|X_{0}(t)-X_{i}(t)\right|+\rho \max _{i} \max _{t}\left|X_{0}(t)-X_{i}(t)\right|}{\left|X_{0}(t)-X_{i}(t)\right|+\rho \max _{i} \max _{t}\left|X_{0}(t)-X_{i}(t)\right|}
$$

$\rho$ means the resolution coefficient which is used reduce the distortion caused by the maximum absolute difference and can make the difference of each correlation coefficient more significant, we take $\rho=0.1$ in the paper (Xu et al., 2013); $\min _{i} \min _{t}\left|X_{0}(t)-X_{i}(t)\right|$ represents the minimum value in twolevel absolute difference, taking the minimum value of absolute difference between each factor $X_{i}$ and RUE $X_{0}$ from the same year firstly, and then taking the minimum among the eight minimum values; Similarly, $\max _{i} \max _{t}\left|X_{0}(t)-X_{i}(t)\right|$ represents the maximum value in two-level absolute difference.

\section{(3) Correlation $r_{i}$}

$$
r_{i}=\frac{1}{15} \sum_{t=1}^{15} \zeta_{X_{i}}(t)
$$

$r_{i}$ means the average of the correlation coefficient for 15 years. According to the principle of Grey relational analysis, the first three factors with the greatest correlation are selected as the dominant factors of desertification.

\section{RESULTS}

\subsection{Spatial distribution of desertification}

The desertification in Ningxia mainly occurs in the central arid zone, followed by the unreachable area of the Yellow River and the abdomen of the irrigated area, and only a small part in the southern region. In view of the fact that desertification is a process, based on the Rainfall Use Efficiency in 2000, according to Sen's trend analysis and M-K non-parametric test, the spatial variation trend of Rainfall Use Efficiency in Ningxia from 2000 to 2014 was calculated by the help of Matlab. With the different confidence levels, the variation trend was divided into five levels: significant degradation, slight degradation, stable, slight improvement, and significant improvement. As shown in Figure 3(a), significant improvement areas were mainly distributed in Xiji, Pengyang, Guyuan, and parts of Lingwu, accounting for $29.88 \%$ of the total area. Slight improvement areas accounted for $55.97 \%$ of the total area. The area where the ecological environment maintained its original shape accounted for $6.36 \%$ of the total area, mainly scattered at the junction of Zhongwei and Haiyuan. Desertification occured in the area where the Rainfall Use Efficiency was degraded, which accounts for $7.79 \%$ of the total area, mainly distributed in Shizuishan, Pingluo, and Yinchuan, Yongning, Qingtongxia, Zhongning, and parts of Jingyuan. In a comprehensive view, the ecological environment in Ningxia has been greatly improved in the past 15 years, and there were only a few areas with ecological degradation.
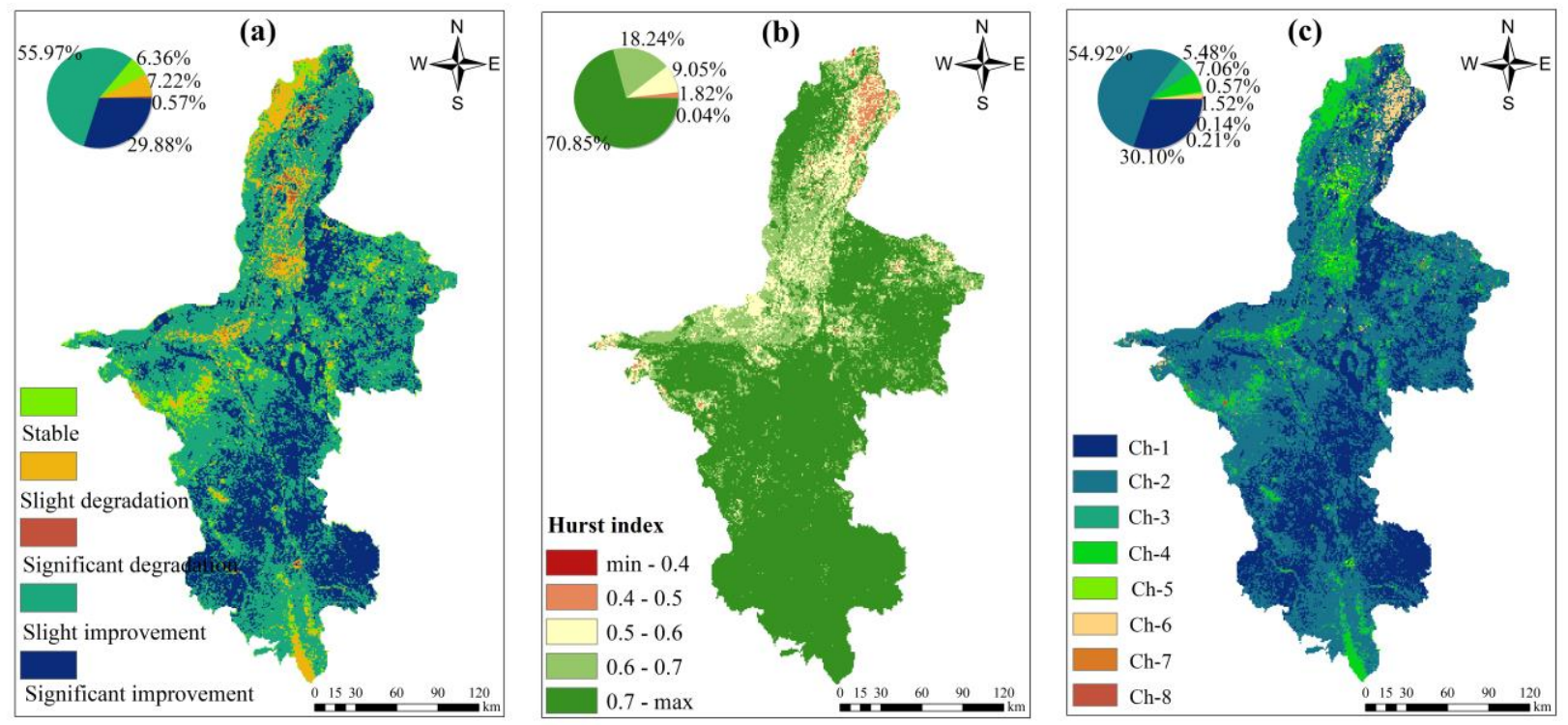

Figure 3. (a)Spatial trend (b) Hurst index (c) Future trend of RUE in Ningxia during 2000-2014(Ch-1: Continuous significant improvement; Ch-2: Continuous slight improvement; Ch-3: Continuous fluctuation; Ch-4: Continuous slight degradation; Ch-5: Continuous significant degradation; Ch-6: Improvement to degradation; Ch-7: Uncertain future trends; Ch-8: Degradation to improvement)

According to the R/S model, Hurst index (3(b)) of RUE in Ningxia was calculated to describe the long-term dependence of the desertification in the time series. The average Hurst index in Ningxia was 0.78 , far exceeding the critical value of 0.5 , indicating that RUE in Ningxia had stronger persistence. From the perspective of spatial distribution, the value of Hurst index was high in the south, and low in the north. Hurst index in the central and southern Ningxia exceeded 0.7, and only the Hurst index of Pingluo and Huinong was below 0.5, which indicated the trend of RUE may be contrary to the past.

Overlaying Hurst index distribution map and the spatial trend map of RUE to obtain the trend of desertification of Ningxia in the future $(3(\mathrm{c}))$. The area where RUE showed continuous 
significant improvement and continuous slight improvement accounted for $30.1 \%$ and $54.92 \%$ of the area respectively, mainly distributed in the south-central part of Ningxia. The areas with continuous slight degradation and continuous significant degradation accounted for $7.06 \%$ and $0.57 \%$ of the total area respectively, which were mainly scattered in Shizuishan, Pingluo,
Yinchuan, Yongning, Wuzhong, Zhongning and Jingyuan. The trend of RUE changed from improvement to degradation in a very small part of Pingluo and Huinong. This area accounted for only $1.52 \%$ of the total area. Therefore, the situation of desertification in Ningxia will continue to improve in the future.

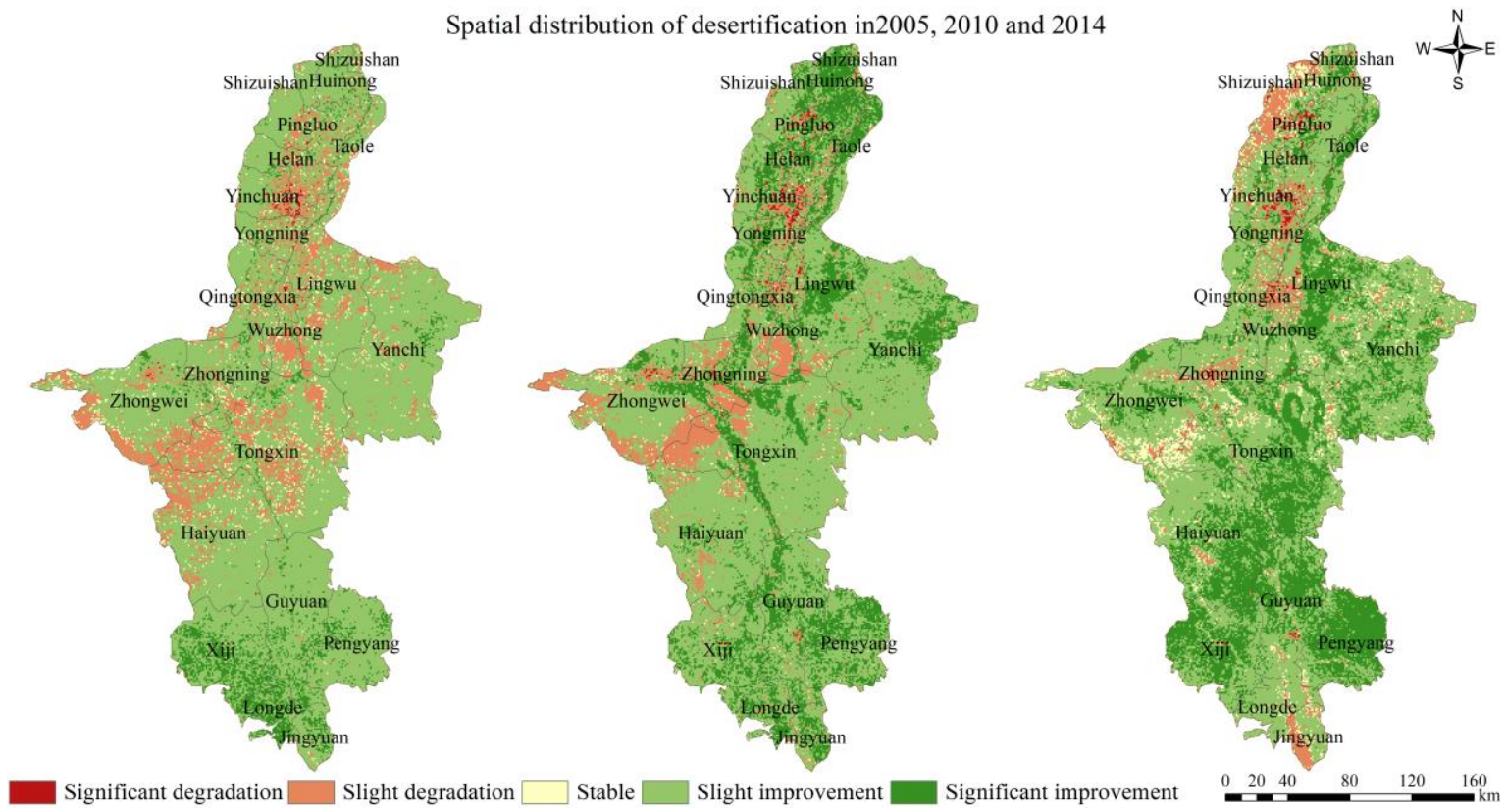

Figure 4. Spatial distribution of desertification in Ningxia in 2005, 2010, 2014

\subsection{Spatial dynamics of desertification}

Based on the data set of RUE in the growing season of Ningxia from 2000 to 2014, the paper studied the process of changes in the ecosystem in Ningxia from the pixel scale, time scale, and regional scale. Based on RUE in 2000, the spatial distribution of desertification in the period 2000-2005, 2000-2010 and 20002014 were calculated respectively.

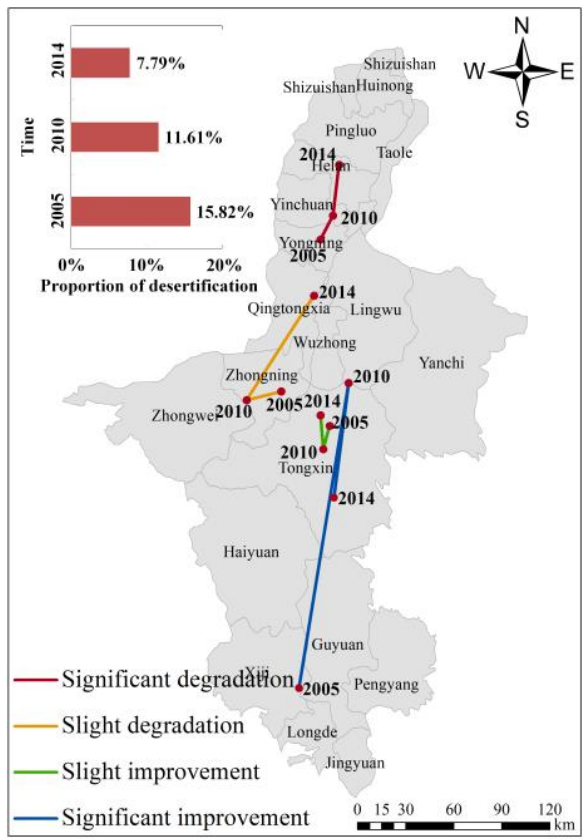

Figure 5. Proportion and gravity migration of desertification in Ningxia from 2005 to 2014
As shown in Figure 4, the areas with improvement in RUE were basically concentrated in the southern Ningxia, while the areas of desertification mainly distributed in Zhongwei, Tongxin, Wuzhong and Yinchuan during 2000-2005, accounting for $15.82 \%$ of the total area. The area with decrease in RUE accounted for $11.61 \%$ of the total area from 2000 to 2010 , which was $4.2 \%$ lower than the proportion of desertification in 2005. The scope of desertification was significantly narrowed and the desertification mainly occurred on the edge of Zhongwei, west of Tongxin, Zhongning, Wu Zhong and Yinchuan in 2010. While the areas with improvement in RUE mainly distributed in the southern mountain and river irrigation areas. The area with decrease in RUE only accounted for $7.9 \%$ of the total area over the period 2000-2014, indicating that the proportion of desertification was further reduced in 2014. The desertification areas were scattered and mainly located in Pingluo, Yinchuan, Wuzhong and very few parts of Jingyuan. In general, the proportion of desertification was decreasing year by year, and desertification areas mainly concentrated in the central Ningxia and the abdomen of the irrigated area.

The center of gravity migration diagram of desertification was drawn in Figure 5. The centers of gravity of significantly and slightly degradation area distributed in central Ningxia and the center of the irrigated area, which was quite consistent with the distribution of desertification. The center of gravity of significantly degradation area migrated northwards during 2005 2010 , with a distance of $17.11 \mathrm{~km}$, and the center of gravity continued to move northwards during 2010-2014, with a distance of $31.94 \mathrm{~km}$. The center of gravity of the slightly degradation area located in Zhongning in 2005 and shifted to the southwest by $22.26 \mathrm{~km}$ in 2010 , and continued to move northwards by 77.65 $\mathrm{km}$ from 2010 to 2014 . Thus, the center of gravity of the desertification had a tendency to move northward. The center of 
gravity of the slight improvement of RUE concentrated in Tongxin, and there was no significant change. While the center of gravity of significant improvement area distributed in Xiji in 2005 , remarkably moved northward in 2010 , and turned to the south in 2014.

\subsection{Driving factors of desertification}

Most of areas (97\%) showed negative correlation between RUE and precipitation, and the regions with significant negative correlation were mainly distributed in the southern and northern Ningxia. There was a positive but not significant correlation between RUE and temperature in the Yellow River irrigated areas and the southern mountain region. The correlation between RUE and temperature were insignificant negative in the central region. On the whole, the effect of temperature on RUE was not obvious. RUE and sunshine hours had a positive correlation

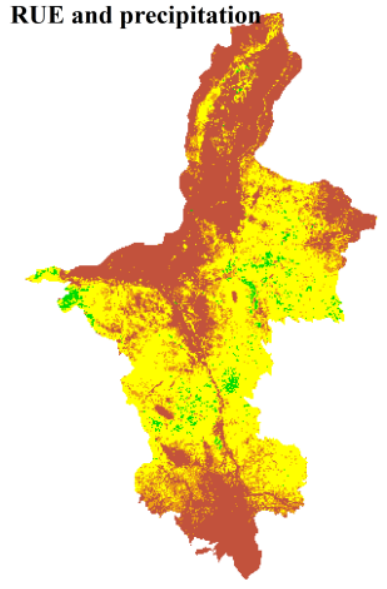

Extremely significant negative correlation

Extremely significant positive correlation

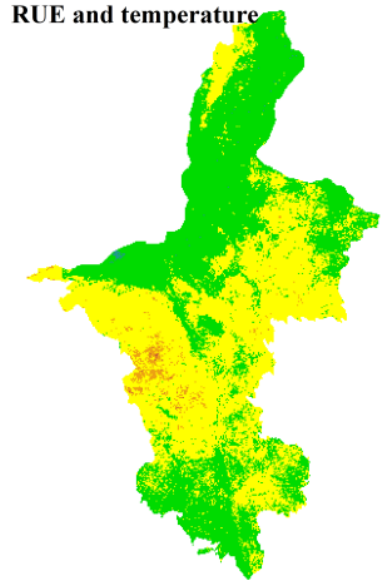

Significant negative correlatio
(Figure 6) in Longde, Jingyuan, Shizuishan, Huinong, Pingluo, Yongning, Qingtongxia, Wuzhong, Zhongwei, Zhongning. There was a negative correlation between RUE and sunshine hours in Yanchi, east of Tongxin, Haiyuan, Guyuan, Xiji and Pengyang where the growth of vegetation had a strong dependence on precipitation, and excessive sunshine hours would affect the normal growth of vegetation. RUE and relative humidity were negatively correlated in most areas, accounting for $73 \%$ of the total area. The areas with extremely significant negative correlation and significant negative correlation accounted for $17 \%$, mainly distributed in Shizuishan, Huinong, Pingluo, Helan, Yinchuan, Yongning, Qingtongxia and Lingwu. There was an insignificant positive correlation between them in Yanchi, Tongxin, Haiyuan and Xiji, which accounted for about $27 \%$ of the total. To a certain extent, the response of RUE to relative humidity was similar to that to precipitation. For most areas, the higher the relative humidity was, the lower RUE was.
RUE and sunshine hours
RUE and relative humidity

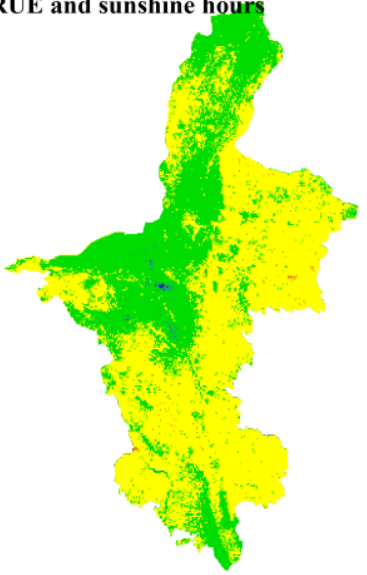

Insignificant negative correlation

Insignificant positive correlation
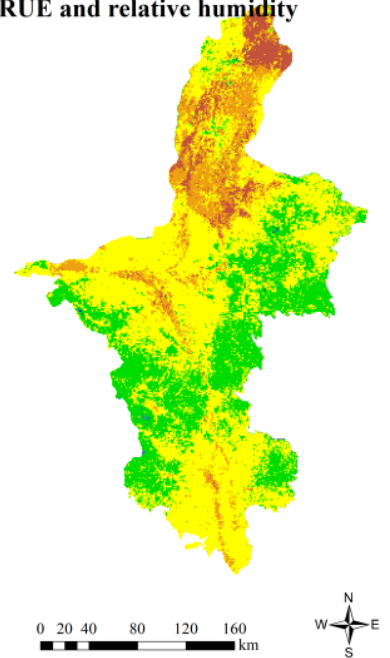

Figure 6. Correlation coefficient of RUE and meteorological factors

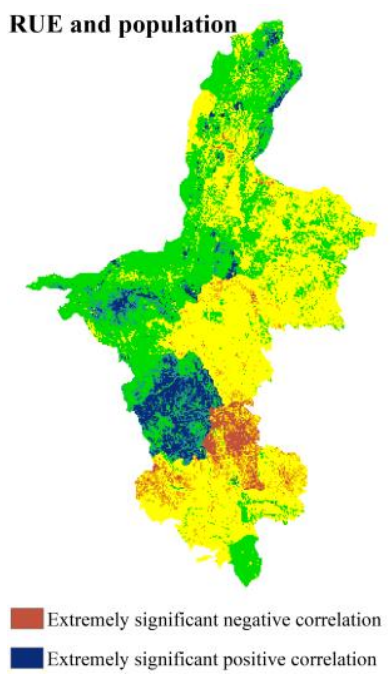

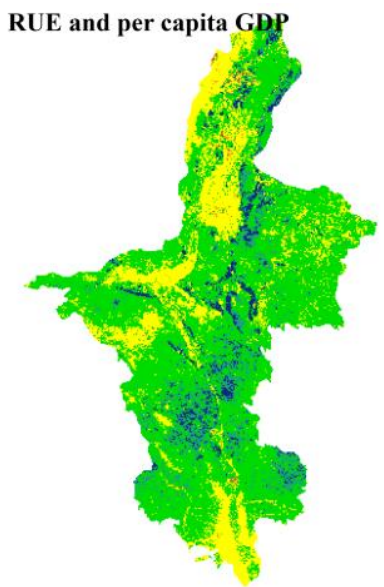

Significant negative correlatio

Significant positive correlation

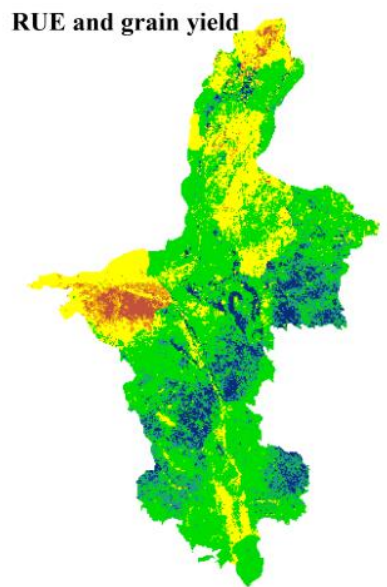

Insignificant negative correlation Insignificant positive correlation

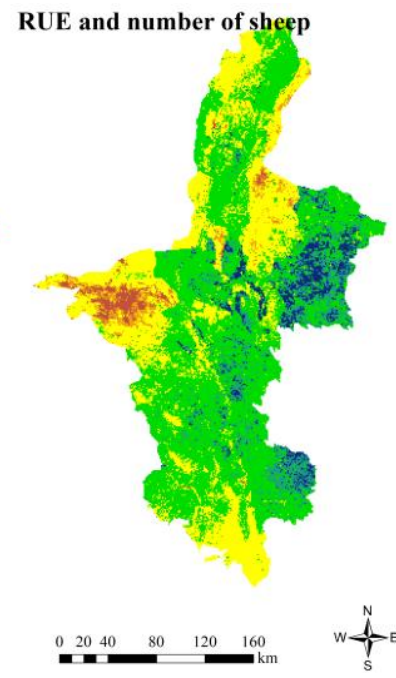

Figure 7. Correlation coefficient of RUE and social factors

Figure 7 shows the correlation coefficient between RUE and population. The area with positive correlation between them accounted for $47 \%$ of the total area which mainly distributed in the northwestern Ningxia, among them, $12 \%$ of the region passed the significance test which mainly distributed in Haiyuan. The area with negative correlation between them distributed in the southeast of Ningxia, and only $7 \%$ passed the significant test which mainly distributed in Guyuan. The correlation between RUE and per capita GDP was not significant in most parts of Ningxia. The proportion of area with positive correlation between them was 76\%, mainly distributed in Huinong, Taole, Lingwu, Yanchi, Zhongwei, Haiyuan, Guyuan, Xiji, and Pengyang. 24\% of the area showed negative correlation between RUE and per capita GDP, which mainly distributed in Jingyuan, 
Longde, Zhongning, northern Wuzhong, estern Qingtongxia, and western Pingluo. Most of the area (73\%) showed positive correlations between RUE and grain yield, mainly in Taole, Pingluo, Qingtongxia, Wuzhong, Zhongning, Yanchi, Tongxin, Haiyuan, Guyuan, Xiji, Pengyang, Longde and Jingyuan. There was a negative correlation between them in Shizuishan, Yinchuan and Zhongwei, which accounted for $27 \%$ of the total area. The area with positive correlation between RUE and number of sheep made up $65 \%$ of the total area, mainly distributed in Huinong, eastern Pingluo, Yinchuan, Yongning, Wuzhong, Zhongning, Yanchi, Tongxin, Haiyuan, Xiji and Pengyang. 35\% of the region showed negative correlations between RUE and number of sheep, mainly in the west of Pingluo, Taole, Lingwu, Zhongwei, Longde, and Jingyuan, especially in Zhongwei where there was a significant negative correlation between them.

In order to identify the dominant factors of desertification, the eight driving factors of RUE were analyzed by grey relational analysis, and the top three were selected. As shown in Figure 8, the analysis showed that sunshine hours account for the largest proportion of the first influencing factors. $23.49 \%$ of the region regarded population as the primary impact factor (Table 1) and mainly located in Haiyuan, scattering in Zhongning and Zhongwei. Temperature accounted for $17.51 \%$ of the first influencing factors. Among the second influencing factors, temperature, sunshine hours and population accounted for $25.80 \%, 21.16 \%$ and $19.41 \%$ respectively. Among the third influencing factors, temperature and sunshine hours were still the main influencing factors, while $22.61 \%$ and $14.72 \%$ of the region regarded the relative humidity and population as the third influencing factor respectively. Therefore, the main driving

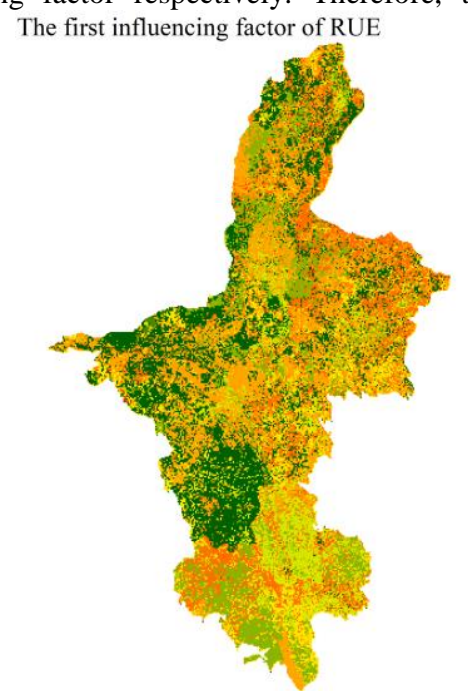

The second influencing factor of RUE

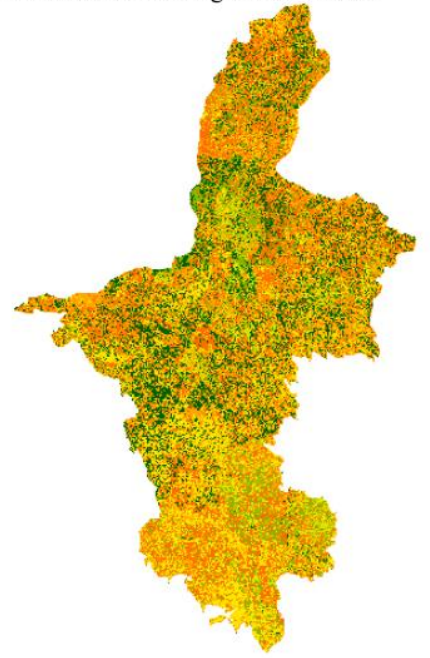

Population

Per capita GDP

Relative humidity

Sunshine hours

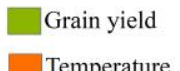

Temperature factors of desertification in Ningxia were temperature and sunshine hours, population and relative humidity also had important impacts on desertification.

The analysis of main driving factors for desertification was mainly to identify the main factors that led to desertification. An overlay analysis of the trend of RUE and the grey relational analysis of driving factors can get the proportion of each driving factor when the ecological environment was significantly degraded and significantly improved (Table 2). Among the significant degradation area, $35.84 \%$ of the region took sunshine hours as the first factor. The proportion of area which regarded population and number of sheep as the first factor was $17.75 \%$ and $12.29 \%$ respectively. Among the second and third factors leading to the positive development of desertification, temperature, relative humidity and sunshine hours were all in the first place. Therefore, the occurrence of desertification was mainly influenced by sunshine hours, temperature and relative humidity. There was a positive correlation between RUE and sunshine hours and relative humidity in this area, the decreasing of sunshine hours and relative humidity and the increasing of temperature led to desertification. Among the first factors affecting the significant improvement in RUE, population accounted for $22.01 \%$. Among the second influencing factors, the largest proportion was temperature, followed by relative humidity and sunshine hours, accounting for $18.87 \%$ and $16.64 \%$ respectively. Among the third influencing factors, the top three factors were still temperature, relative humidity and sunshine hours. Therefore, the improvement of RUE was mainly affected by the population, temperature, relative humidity and sunshine hours.

Figure 8. The first, second and third influencing factor of the change of RUE

\begin{tabular}{|c|c|c|c|c|c|c|c|c|}
\hline & Precipitation & Temperature & $\begin{array}{c}\text { Sunshine } \\
\text { hours }\end{array}$ & $\begin{array}{c}\text { Relative } \\
\text { humidity }\end{array}$ & $\begin{array}{c}\text { Number } \\
\text { of sheep }\end{array}$ & $\begin{array}{c}\text { Grain } \\
\text { yield }\end{array}$ & $\begin{array}{c}\text { Per capita } \\
\text { GDP }\end{array}$ & Population \\
\hline $\begin{array}{c}\text { First } \\
\text { factor }\end{array}$ & 0.26 & 17.51 & 24.24 & 11.80 & 9.45 & 12.81 & 0.43 & 23.49 \\
\hline $\begin{array}{c}\text { Second } \\
\text { factor }\end{array}$ & 0.36 & 25.80 & 21.16 & 17.61 & 6.16 & 9.22 & 0.28 & 19.41 \\
\hline $\begin{array}{c}\text { Third } \\
\text { factor }\end{array}$ & 0.68 & 28.10 & 20.42 & 22.61 & 5.27 & 7.88 & 0.32 & 14.72 \\
\hline
\end{tabular}

Table 1. Percentage of dominant factors affecting RUE changes (\%) 
The International Archives of the Photogrammetry, Remote Sensing and Spatial Information Sciences, Volume XLII-3, 2018 ISPRS TC III Mid-term Symposium “Developments, Technologies and Applications in Remote Sensing”, 7-10 May, Beijing, China

\begin{tabular}{|c|c|c|c|c|c|c|}
\hline \multirow{2}{*}{ Impact factor } & \multicolumn{3}{|c|}{ Significant degradation } & \multicolumn{3}{c|}{ Significant improvement } \\
\cline { 2 - 7 } & First factor & Second factor & Third factor & First factor & Second factor & Third factor \\
\hline Precipitation & 2.39 & 2.39 & 3.75 & 0.21 & 0.45 & 1.12 \\
\hline Temperature & 11.26 & 34.47 & 26.62 & 20.57 & 27.12 & 27.05 \\
\hline Sunshine hours & 35.84 & 19.11 & 21.50 & 12.98 & 16.64 & 21.39 \\
\hline Relative humidity & 10.24 & 17.41 & 24.57 & 9.25 & 18.87 & 22.26 \\
\hline Number of sheep & 12.29 & 3.07 & 5.46 & 16.23 & 9.84 & 6.26 \\
\hline Grain yield & 10.24 & 6.83 & 5.46 & 17.83 & 12.12 & 8.75 \\
\hline Per capita GDP & 0.00 & 0.00 & 0.34 & 0.91 & 0.53 & 0.68 \\
\hline Population & 17.75 & 16.72 & 12.29 & 22.01 & 14.43 & 12.49 \\
\hline
\end{tabular}

Table 2. Percentage of dominant factors in the area RUE significantly changing (\%)

\section{CONCLUSIONS AND DISCUSSION}

\subsection{Dynamic analysis of desertification}

The desertification dynamics studied in this paper were mainly reflected by the trend of Rainfall Use Efficiency (Symeonakis et al., 2004), which can not only directly reflect the production capacity of the land and can also make certain improvements in response to the large impact of precipitation on the vegetation in arid regions (Gao et al., 2005). The paper mainly used the changes in RUE to characterize the occurrence of land desertification, fully embodying the dynamic characteristics of desertification. The desertification areas in Ningxia during 20002014 were mainly concentrated in Helan Mountain, Liupan Mountain and the abdomen of the irrigated area. Most areas showed an improvement in RUE, which had a lot to do with climate change, human activities, cultural education and policy implementation in Ningxia, indicating that the ecological construction has achieved positive results at this stage.

At the same time, RUE in most areas had strong dependence on the trend, indicating that most areas of Ningxia had strong ecological restoration capabilities. The changes reflected by the Hurst index were the result of the combined effects of human and natural factors. However, with the increase of global warming and human activities, there were some uncertainties in its future changes. From the perspective of the spatial distribution of desertification at different time scales, the proportion of desertification decreased gradually from 2005 to 2014, and both the significantly degraded and slightly degraded centers of gravity migrated to the northern Ningxia, indicating that the desertification area had a tendency to shift to the north. The Yellow River irrigation area in the north was convenient for irrigation, and agriculture was relatively developed, but as the capital of Ningxia, Yinchuan has implemented the "Great Yinchuan" strategy and "two most suitable projects" in recent years, which led to the rapid urbanization and rapid increase in population and may had an impact on the ecological environment (Zhao et al., 2017). To be sure, this requires further collection of more updated data for further study.

\subsection{Driving factors of desertification}

Land desertification is the result of many factors such as nature and society. In recent years, the economic development of Ningxia is faster, development mode backward economy s of various traditional agriculture and animal husbandry have undergone a transformation and human activities have been strengthened. Therefore, the factors that affect the ecological environment are more diverse. From the perspective of natural factors, RUE had a negative correlation with precipitation overall, and Ye Hui et al. also found that RUE decreased as the precipitation increased in the more drier and more humid regions (Ye et al., 2012; Mu et al., 2014). Suggesting that RUE can be separated from precipitation and characterize the state of desertification. With the decrease of precipitation, vegetation coverage decreased (Zhao et al., 2016), but it did't mean that desertification occurred in this region, which only showed the response of vegetation to precipitation. In contrast, the increase of precipitation may have inhibitory effect on photosynthesis of vegetation and cause the loss of nutrients in soil, thus leading to the reduction of RUE. The correlations between RUE and temperature and sunshine hours were not significant in most regions. RUE and relative humidity had a positive correlation in the most of areas, which was similar to the distribution of correlation coefficient between RUE and precipitation. From the perspective of social factors, the regions with positive correlations between RUE and population were mainly distributed in the Yellow River irrigation district and Haiyuan where the population increased. The area was dominated by the development of agriculture and RUE increased with the increase of population and agricultural inputs. RUE and population had a negetive correlation in the southeastern Ningxia. Because the southern region had a relatively backward economy and a low level of accepting culture, the increase of people was bound to increase unreasonable human activities. There was a positive correlation between per capita GDP and desertification in most regions, indicating that the ecological environment has also been improved in the development of economy in Ningxia in recent years. The region dominated by cultivated field showed positive correlation between RUE and grain yield, while RUE of grassland and woodland was negatively correlated with grain yield. The area with positive correlation between RUE and number of sheep accounted for $65 \%$ of the total area, which attributed to the development of animal husbandry. There was a negative correlation between them where number of sheep was small and was dominated by desertification pastures. Therefore, the reduction in number of sheep would bring about ecological improvement.

According to grey relational analysis, the main factors affecting the change of RUE were temperature, sunshine hours, population and relative humidity. The occurrence of desertification was due to the decrease of sunshine hours and relative humidity, the increase in temperature and population and the reduction in the 
number of sheep were also factors that contribute to desertification. Of course, with the development of society and economy, the strengthening of human activities and the acceleration of urbanization, desertification is affected by various factors. In the future, the impact of each factor on desertification should be analyzed from a microscopic perspective and this will also be the focus of follow-up research.

\section{REFERENCES}

Barrio, G.D., Puigdefabregas, J., Sanjuan, M.E., et al., 2010. Assessment and monitoring of land condition in the Iberian Peninsula, 1989-2000. Remote Sensing of Environment, 114(8), pp. 1817-1832.

Fensholt, R., Rasmussen, K., 2011. Analysis of trends in the Sahelian 'rain-use efficiency' using GIMMS NDVI, RFE and GPCP rainfall data. Remote Sensing of Environment, 115(2), pp. 438-451.

Gao, Z., Li, Z., Ding, G., Li, L., 2005. New approach for desertification assessment by remote sensing based upon Rain Use Efficiency of vegetation. Science of soil and water conservation, 3(2), pp. 37-41.

Gu, Z., Shi, P., Chen, J., 2006. Precipitation interpolation research over regions with sparse meteorological station: a case study in Xinlin Gole League. Journal of Beijing Normal University(Natural Science), 42(2), pp. 204-208.

Hountondji, Y.C., Sokpon, N., Ozer, P., 2006. Analysis of the vegetation trends using low resolution remote sensing data in Burkina Faso (1982-1999) for the monitoring of desertification. International Journal of Remote Sensing, 27(5), pp. 871-884.

Jiang, Z., An, L., Chai, C., 2008. Quantitative study on influencing factors of desertification in Minqin County, Gansu Province. Journal of Desert Research, 28(1), pp. 35-38.

Kang, W., Liu, S., 2014. A review of remote sensing monitoring and quantitative assessment of Aeolian desertification. Journal of Desert Research, 34(5), pp. 1222-1229.

Li, H., Liu, G., Fu, B., 2011. Response of vegetation to climate change and human activity based on NDVI in the Three-River Headwaters region. Acta Ecologica Sinica, 31(19), pp. 54955504 .

Mu, S., Zhou, K., Qi, Y., Chen, Y., Fang, Y., Zhu, C., 2014. Spatio-temporal patterns of precipitation-use efficiency of vegetation and their controlling factors in Inner Mongolia. Chinese Journal of Plant Ecology, 38(1), pp. 1-16.

Peng, F., Wang, T., Xue, X., 2010. Study of human impact on vegetation in desertified regions based on Rainfall Use Efficiency. Journal of Desert Research, 30(4), pp. 896-902.

Piao, S., Fang, J., Liu, H., et al., 2005. NDVI - indicated decline in desertification in China in the past two decades. Geophysical Research Letters, 32(6), pp. 347-354.
Sun, J., Wang, T., Yan, C., 2012. The relative roles of climate change and human activities in desertification process. Journal of Desert Research, 32(3), pp. 625-630.

Symeonakis, E., Drake, N., 2004. Monitoring desertification and land degradation over sub-Saharan Africa. International Journal of Remote Sensing, 25(3), pp. 573-592.

Wang, L., Niu, Z., Wei, Y., 2007. Land cover type classification and potential desertification area detecting in Xinjiang based on MODIS NDVI imagery. Arid Land Geography, 114(4), pp. 573578.

Wang, Z., Wu, Y., Liang, F., Chang, S., Shi, Q., 2011. Study on spatial interpolation method of annual precipitation in Xinjiang. Chinese Journal of Agrometeorology, 32(3), pp. 331-337.

Wei, Z., Ren, Z., Zhang, C., Zhang, J., 2014. The spatial and temporal pattern of desertification in 1999-2010 in the ShanxiGansu-Ningxia Region. Journal of Desert Research, 34(5), pp. 1230-1236.

Wen, X., Liu, Y., Yang, X., 2015. A resilience-based analysis on the spatial heterogeneity of vegetation restoration and its affecting factors in the construction of eco-cities: a case study of Shangluo, Shaanxi. Acta Ecologica Sinica, 35(13), pp. 4377 4389 .

$\mathrm{Xu}$, S., 2013. Spatial-temporal change of vegetation in the western Songliao Plain based on NDVI and RUE. Northeast Normal University, Jilin, China.

Ye, H., Wang, J., Huang, M., Qi, S., 2012. Spatial pattern of vegetation precipitation use efficiency and its response to precipitation and temperature on the Qinghai-Xizang Plateau of China. Chinese Journal of Plant Ecology, 36(12), pp. 1237-1247.

Yin, H., Li, Z., Wang, Y., Cai, F., 2011. Assessment of desertification using time series analysis of Hyper-temporal vegetation indicator in Inner Mongolia. Acta Geographica Sinica, 66(5), pp. 653-661.

Zhang, X., Wang, D., 2013. Quantitative analysis of driving factors on desertification in agriculture pasture ecotone of Longdong region of Loess Plateau of China. Chinese Journal of Soil Science, 44(2), pp. 296-301.

Zhao, Z., Zhang, L., Wang, S., 2016. Correlation between NDVI and meteorological factors of different vegetation types in Ningxia. Science of Surveying and Mapping, 41(7), pp. 98-103.

Zhao, Z., Zhang, L., Li, X., Wang, Y., Wang, S., 2017. Monitoring vegetation dynamics during the growing season in Ningxia based on MOD13Q1 data. Progress in Geography, 36(6), pp. 741-752.

Zhou, F., 2010. Study on dynamic change of vegetation and desertification assessment in plain of Qitai County. Xinjiang University, Xinjiang, China. 